\title{
Stress in Working Women Due to Lockdown: A Cross Sectional Survey
}

\author{
Manjeet Singh ${ }^{1}$, Rabab Kaur ${ }^{2}$ \\ ${ }^{1}$ Student, Galgotias University, ${ }^{2}$ Assistant Professor, Galgotias University, Plot No. 2, Yamuna Expy, \\ Opposite, Buddha International Circuit, Sector 17A, Greater Noida, Uttar Pradesh 203201
}

\begin{abstract}
Background and Purpose: Due to the vast spread of coronavirus, the lockdown has been announced in many countries, and hence many people are facing psychological, physical, economic and social issues. It has targeted all the population but this study focuses on the increased amount of perceived stress on women who are undergoing work from home pattern of occupation.

Methodology: Sample comprised of 110 working women. The structured questionnaire, Perceived Stress Questionnaire, was circulated through online google forms. Along with stress, demographic sheet was used to study stress in working women due to lock down.

Result: The outcome, view of the respondents based on feeling of anxiety of working ladies was classified into 3 categories (Mild, Moderate, Severe) and range. 7 persons of respondents are in $0.01-0.40$ range i.e. $6.36 \%, 101$ persons of respondents are in $0.40-0.70$ range i.e. $91.81 \%, 2$ persons of respondents are in $0.70-1.00$ range i.e. $1.81 \%$.
\end{abstract}

Conclusion: In this investigation we found that a large population of the females are under moderate pressure and are overstressed while carrying out work from home.

Keywords: Stress, PSQ (Perceived Stress Questionnaire), COVID 19, Lockdown, coronavirus.

\section{Introduction}

'Stress' word has been subordinate from material science and mechanics where it is particularly portrayed as physical weight applied upon, and between different bits of body, when bending occurs as conclusive item it is called strain. ${ }^{1}$ Stress is a disagreeable and widespread experience which is influences every one of us in various manners and at various occasions in the present supercharged working environment. Ladies are additionally almost certain than men to be unfavorably influenced by mental clutters. Employment stress is characterized as the hurtful enthusiastic and physical reaction which happens because of prerequisites of the activity don't coordinate the abilities, assets, or requirements of the laborer. It is extensive proof that the worry because of double job of ladies at a work spot and home and that innate in contrarily impacts their personal satisfaction. $^{2}$

After freedom, ladies in India have made some amazing progress. From only a master homemaker/ housewife, she not just has gained aptitudes and capacities to being an ideal housewife however being at same level with their companion or life accomplice. Presently, ladies need to catch up their fantasy vocation and this is the new proliferation of working ladies. ${ }^{3,1}$ The Industrial Revolution to some degree was fuelled by the financial need of numerous ladies, single and wedded, they are found pursued work outside their home. Generally, ladies secured positions in local assistance, piece workshops, and material manufacturing plants. They are likewise worked in the coal mineshafts. For a few, the Industrial Revolution gave free wages, portability and a superior way of life. ${ }^{4}$ In India, post globalization, there is unmistakable changes in perspectives of ladies and the general public's viewpoint towards them. In the course of recent decades that has been a continuous acknowledgment of work jobs in ladies. Over the globe, ladies are venturing out of the security of their homes to confront difficulties of more up to date sorts. ${ }^{5}$ Along 
these lines doing obligations and duties both at home and working environment overstrains a wedded working lady, in this manner prompting different mental issues like job struggle, work strain, mental weariness, stress, uneasiness, disappointment, sadness, outrage, fears, and other social and passionate pain. These issues can intelligently influence the psychological prosperity of working ladies and all the more so in wedded working ladies. $^{6}$

Lockdown, a term routinely utilized as proxy for "mass isolate", is normally founded on "stay-at-home" or "safe house set up" laws given by an open (either national or provincial) government or authority, for forcing social removing and subsequently constraining or totally canceling the development of the populace inside and outside a particular zone. It is consequently generally utilized with respect to balancing a progressing episode, ordering occupants to remain inside their homes, aside from doing basic exercises (wellbeing visits, keeping an eye on a helpless individual, buying prescriptions, food and drinks) or giving basic work (for example medicinal services and social consideration areas, police and military, firefighting, water and power flexibly, basic assembling). Other insignificant exercises are thus halted or done from home. ${ }^{7}$ In a male driven culture like India it is as yet acknowledged that a man is the fundamental supplier of his family. But Indian women have started working outside their home yet simultaneously they have far to go both socially, socially and fiscally, to get productive attitudinal changes in the mindset of people. ${ }^{8}$ Anxiety, stress and oppressive indications are normal in a combination of mental states (Kvaal et al. 2005). In connection with men, women are will undoubtedly make strain issue over their future (Bruce et al. 2012; Mclean and Hofmann 2012). According to the US National comorbidity review, the lifetime inescapability rates for any apprehension issue were $19.2 \%$ for men and $30.5 \%$ for women (Mclean and Hofmann 2012). ${ }^{9}$ The conventional arrangement of male prevalence or male overwhelmed cultural set up makes various difficulties ladies at their work place. It is an inborn conviction that ladies' work capacity and productivity is lesser than men. The youthful female age has changed the intrinsic male centric structure on ladies in the general public that was getting common until the finish of the twentieth century in India. ${ }^{10} \mathrm{We}$ conjectured that more significant levels of pressure and more manifestations of wretchedness or tension would be related with expanded normal cortisol levels and a smoothed diurnal cortisol design. ${ }^{11}$ At the point when everything is said in done, women are practically sure than men to experience physical appearances of worry, for instance, shortcoming, instability, cerebral agonies, and wretchedness. Women are furthermore more likely than men to adjust to work stress with bothersome practices, for instance, helpless dietary examples. ${ }^{12}$ A significant issue in exploring the pressure issue connection is the contiguity between upsetting occasions and turmoil. ${ }^{13}$ The lockdown - in full power as we compose - limits 1.3 billion individuals from leaving their homes. Transport administrations are suspended, instructive organizations are shut, and manufacturing plants are closed down. This is in accordance with the measures forced in most European nations and in the United States, however the sheer size of the measure - as on account of most approaches in India - is threatening. ${ }^{14}$

\section{Methodology}

This chapter discussed the process used for the analysis which provides explanation of the topics used in data collection and analysis. A Cross- Sectional Survey was carried out. Sample size of 110 working females were taken. The data has been collected through structured questionnaire using online google form by working women. Stratified random sampling method.

\section{Inclusion Criteria:}

1. Gender - Females

2. Age -25 to 60 years

3. Able to understand English

\section{Exclusion Criteria:}

1. Pregnant women

2. People who have difficulty in understanding English or other communication issues

3. The population having any neurological issues

Data Analysis: The essential information was gathered by conveying a poll among the working ladies by means of google structure, the individuals who are adhered at home because of lockdown in India. The investigation was led between April-May 2020. Information were gathered by various angles identified with the work environment, factors adding to pressure, indications and outcomes of stress and diverse adapting methodologies received by working ladies to manage pressure. ${ }^{1}$ 
Understanding of Data: The understanding of the information was investigated through rate as information has been accumulated from 110 respondents. It was done in the accompanying way:

Table 1 Age assumes a significant job in worry among working ladies. The age of the respondents is arranged into three classifications. Table 4.1 shows that out of 110 respondents, $81 \%$ are in the age gathering of $30-40,14.4 \%$ are in the age gathering of $40-50,4.5 \%$ are in the age gathering of 50-60.
Table 1: Age group of females

\begin{tabular}{|c|c|c|}
\hline Age & No. of Respondents & Percentage (in \%) \\
\hline $25-40$ & 89 & 81 \\
\hline $40-50$ & 16 & 14.4 \\
\hline $50-60$ & 5 & 4.5 \\
\hline Total & $\mathbf{1 1 0}$ & $\mathbf{9 9 . 9}$ \\
\hline
\end{tabular}

Table 2: Mental and physiological side effects of worry among working ladies in Lockdown

\begin{tabular}{|c|l|c|c|c|c|}
\hline Total & Stress Symptoms & Almost & Sometimes & Often & Usually \\
\hline 110 & You feel rested & 15 & 75 & 17 & 3 \\
\hline 110 & You feel you are doing things you really like & 24 & 38 & 45 & 3 \\
\hline 110 & You feel calm & 32 & 48 & 26 & 4 \\
\hline 110 & You are full of energy & 17 & 48 & 39 & 6 \\
\hline 110 & You feel safe and protected & 19 & 46 & 31 & 14 \\
\hline 110 & You enjoy yourself & 18 & 42 & 39 & 11 \\
\hline 110 & You are lighthearted & 11 & 55 & 35 & 9 \\
\hline 110 & You have enough time for yourself & 13 & 52 & 36 & 9 \\
\hline
\end{tabular}

Table 2 shows the consequence of information gathered from 110 respondents based on mental and physiological manifestations of worry among working ladies. $13.63 \%$ respondents said that they feel rested because of stress, while $68.18 \%$ said that occasionally and $15.45 \%$ feel regularly and $2.72 \%$ normally. $3.63 \%$ respondents said that they typically feel issue of quiet.

Table 3: Qualification of women

\begin{tabular}{|l|c|c|}
\hline Qualification & $\begin{array}{c}\text { Number of } \\
\text { women }\end{array}$ & $\begin{array}{c}\text { Percentage } \\
\text { (in \%) }\end{array}$ \\
\hline Teacher & 45 & 40.9 \\
\hline Engineer & 18 & 16.3 \\
\hline Private limited company & 30 & 27.2 \\
\hline Other service(s) & 17 & 15.4 \\
\hline Total & 110 & 100 \\
\hline
\end{tabular}

Table 3 shows the view of the respondents based on their capability. It is characterized into 4 classes. $40.9 \%$ of respondents are instructors, $16.3 \%$ of respondents are engineer, $27.2 \%$ of respondents are private constrained organization and rest $15.4 \%$ have other expert help.
Table 4: Stress Level of Working Women

\begin{tabular}{|l|c|c|c|}
\hline Description & Range & Person & Percentage (in \%) \\
\hline Mild & $0.01-0.40$ & 7 & 6.36 \\
\hline Moderate & $0.40-0.70$ & 101 & 91.81 \\
\hline Severe & $0.70-1.00$ & 0 & 1.81 \\
\hline Total & & $\mathbf{1 1 0}$ & $\mathbf{9 9 . 9}$ \\
\hline
\end{tabular}

Table 4 shows the outcome, view of the respondents based on anxiety of working ladies. It is arranged into 3 classes (Mild, Moderate, Severe) and go. 7 man of respondents are in $0.01-0.40$ territory and $6.36 \%, 101$ man of respondents are in $0.40-0.70$ territory and $91.81 \%, 2$ man of respondents are in $0.70-1.00$ territory and $1.81 \%$.

\section{Discussion}

In the current investigation, while the privately settled working women uncovered more satisfaction than working women, the past scored lower on certainty (both saw and socially observed), which shows that working from home could be both liberating and restricting. Though privately arranged working ensured versatility, 
it impacted the women's needs to develop themselves full-time into their callings, harden their financial selfrule and not wait behind their companions, which were as strong as that of their working accomplices (Rani, 1976). It was found that family stress, family difficulty, and work-family work over-trouble can transform into a grave issue for the working woman and can have a negative impact upon her general prosperity, work execution, and occupation satisfaction. ${ }^{4}$ An investigation on data innovation area working ladies which utilized authoritative job pressure scale detailed higher feeling of anxiety as the age expanded, a finding rather than our examination. To restrict the apprehension issue, there should be a fine agreement between the quality and whole of information one needs to extend. Information from unconfirmed sources and web-based life stages make sure to cause furious and make you annoyed. Obliging on the web life use can in like manner be a guide to our mind and enthusiastic health. ${ }^{19}$ This examination shows that high paces of depression, anxiety, insomnia and perceived pressure, with young ladies having higher chances of embracing a psychological well-being result. These results were related with various COVID19-related hazard factors, including being under isolate, having a friend or family member perished by COVID-19, the working movement stopped because of lockdown gauges, or encountering other upsetting occasions (for example working, budgetary, relationship or lodging issues) because of the pandemic or lockdown measures. $^{20}$

\section{Limitations of the study:}

1. Small sample size

2. Study was for a short span of time

3. The study was only a one-time survey

\section{Recommendations:}

1. This study can be performed on a larger sample size

2. The duration of the study can be longer

\section{Conclusion}

Work related pressure is a major task for working ladies in the lockdown. As quantities of working ladies are expanding in training area, they need to manage difficulties like long working hours, job challenges, lack of oversight, poor relationship with partners, remaining task at hand, role struggle, lack of chance for development and progression and occupation disappointment. Also, it isn't just critical to distinguish reasons of pressure and to bargain with them however to empower solid work and diminished dangerous parts of work. Instructive establishments need toconsider the requests of adjusting worry among working ladies to make nature increasingly steady, which will be useful to hold gifted, able and experienced working ladies. The board must work for preparing and instructing, coaching, consistent picking up, directing, open doors for profession improvement, procedures of time the board to deal with their outstanding task at hand at home along with work spot to inspire them to take higher duties. The fundamental discoveries of the study show that all the respondents have trouble because of individual and hierarchical sources. Dealing with the everyday home exercises, kid care and caring for the family individuals are the central point which cause trouble among the working school ladies. ${ }^{1}$

Ethical Clearance: Taken from University Ethical Committee.

\section{Source of Funding: Self}

\section{Conflict of Interest: Nil}

\section{References}

1. Sharma B, Nair M. A qualitative study on causes and effects of stress among working women in management colleges in Jaipur. International Journal of Current Advanced Research. 2015:(152).

2. MAMTA PARASHARA, MITASHA SINGHA,*, JUGAL KISHOREB, RAMBHA PATHAKA, MEELY PANDA. Prevalence and correlates of stress among working women of a tertiary health center in Delhi, India (FEBRUARY 2017) (1)

3. PROF. PARUL TRIPATHI*; PROF. SANDEEP BHATTACHARJEE** A STUDY ON PSYCHOLOGICAL STRESS OF WORKING WOMEN Vol.2 Issue 2, February 2012, ISSN 2231 5780 (434(1))

4. MALAVIKA DESAI, BISHAKHA MAJUMDAR, TANUSREE CHAKRABORTY, KAMALIKA GHOSH Working women in INDIA, https://doi. org/10.1108/17542411111164920 (2011) (432)

5. Panigrahi A, Padhy AP, Panigrahi M. Mental health status among married working women residing in Bhubaneswar City, India: a psychosocial survey. BioMed research international. 2014;2014.

6. PRIYANKA PULLA, Covid-19: India imposes lockdown for 21 days and cases rise, BMJ 
2020;368:m1251 doi: 10.1136/bmj.m1251

(Published 26 March 2020) (1)

7. Lippi G, Henry BM, Bovo C, Sanchis-Gomar F. Health risks and potential remedies during prolonged lockdowns for coronavirus disease 2019 (COVID-19). Diagnosis. 2020 May 26;7(2):85-90..

8. Kumari V. Problems and challenges faced by urban working women in India (Doctoral dissertation).2014 (8)

9. Patel PA, Patel PP, Khadilkar AV, Chiplonkar SA, Patel AD. Impact of occupation on stress and anxiety among Indian women. Women \& health. 2017 March (2)

10. Pratheep S, Dharmaraj A. An empirical study on stress levels among working women in export oriented units of Tirupur district. Man In India. 2016 (3079)

11. Kurina LM, Schneider B, Waite LJ. Stress, symptoms of depression and anxiety, and cortisol patterns in working parents. Stress and Health: Journal of the International Society for the Investigation of Stress. 2004 Apr;20(54).

12. Kermane MM. A psychological study on stress among employed women and housewives and its management through progressive muscular relaxation technique (PMRT) and mindfulness breathing. J PsycholPsychother. 2016 Jan (1).

13. Brantley PJ, Dietz LS, McKnight GT, Jones GN, Tulley R. Convergence between the Daily Stress Inventory and endocrine measures of stress. Journal of consulting and clinical psychology. 1988 Aug; (549).
14. World Health Organization. Mental health and psychosocial considerations during the COVID-19 outbreak, 18 March 2020. World Health Organization; 2020

15. Lu J. A New, Simple Projection Model for COVID-19 Pandemic. medRxiv. 2020 Jan 1.

16. Bakshi P, Kochhar V. A Study and Evaluation of Stress Role on Faculty: An Analysis of Professional Institutions in Haryana. International Journal of Research in IT \& Management. 2012;2(6):71-9.

17. Patel PA, Patel PP, Khadilkar AV, Chiplonkar SA, Patel AD. Impact of occupation on stress and anxiety among Indian women. Women Health. 2017;57(3):392-401. doi:10.1080/03630242.2016. 1164273

18. Melchior M, Caspi A, Milne BJ, Danese A, Poulton $\mathrm{R}$, Moffitt TE. Work stress precipitates depression and anxiety in young, working women and men. Psychological medicine. 2007 Aug.

19. Patnaik NM, Maji S. Psychological Issues and Stress on People in the Purview of COVID-19 Pandemic Lockdown.2020 May (39)

20. Rossi R, Socci V, Talevi D, Mensi S, Niolu C, Pacitti F, Di Marco A, Rossi A, Siracusano A, Di Lorenzo G. COVID-19 pandemic and lockdown measures impact on mental health among the general population in Italy. An $\mathrm{N}=18147$ webbased survey. medRxiv. 2020 Jan 1. 